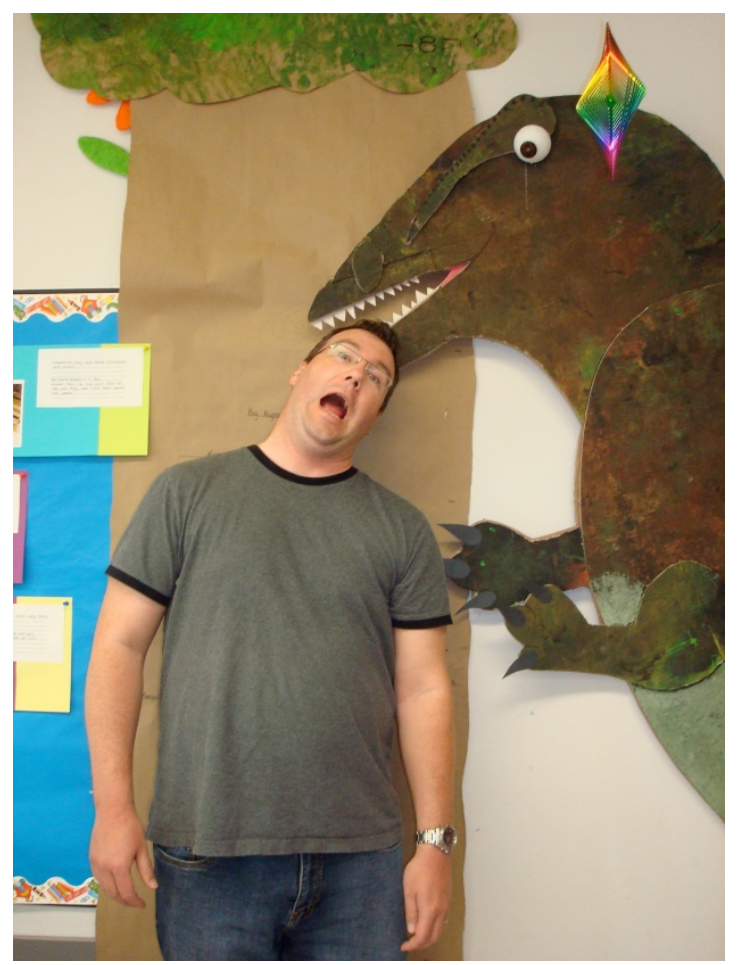

\title{
Profile: Jason Hammond
}

\author{
Branch Head, Regent Place \\ Regina Public Library (RPL) \\ Regina, Saskatchewan
}

\section{Describe your early background:}

I grew up in a small town called Indian Head, Saskatchewan. After graduating high school, I moved to Regina where I completed a BA English. I ended up working in the book publishing industry for nearly a decade-first in Saskatchewan and then in Alberta-but always had the idea of doing an MLIS in the back of my head. I ended up applying to Western in late 2005 and completed their accelerated Master's program in 2006.

\section{What (or who) influenced you to pursue a career in libraries?}

The most direct influence on my current career was a fellow student I met while on a university exchange to England in 1995. She was from Chicago and, after finishing her undergrad degree, was planning to go directly into an MLIS program. That was the first time that doing an MLIS became a serious consideration for me-although, unlike her, it took me another ten years to act on that idea!

\section{What is your most memorable library experience?}

A recent memorable experience was having the daughters of a patron who'd passed away bring us one final order of Tim Hortons doughnuts and coffee in memory of their dad, who often did this for us throughout the year. Their dad was a regular user of our branch and it was nice that they recognized how much our library meant to him, going so far as to thank the library in his obituary.

\section{Where are you working now, and what do you like best about your current job?}

I am currently the Branch Head for a public library in Regina, a position I've been in for a year and a half. There are quite a few things I like about this job. My branch is the newest branch in our system, having only been open at its current location for a couple years, so it integrates a lot of the latest ideas in library design and technology. I love the 
wide variety of interactions and activities you have every single day. And on a selfish note, I love that this branch is only a few minutes from my home so I get to see my wife at lunch pretty much every day!

\section{What do you do for fun?}

I collect books about The Beatles which allows me to combine two of my interests in a single hobby.

Tell us about an interesting book or article you've read recently. What appealed to you about it?

How Google Works by Eric Schmidt and Jonathan Rosenberg. I think libraries could learn a lot about how to thrive as a twenty-first-century organization by taking a look at what the most successful tech companies are doing.

\section{What accomplishment are you most proud of?}

Winning the peer-nominated "Spirit of Librarianship" award during my first semester of library school was a nice vote of confidence that l'd made the right choice in deciding to go back to school after ten years in the working world.

\section{What issues do you think will have a big impact on libraries in the next few years?}

There are tons of things that could have a huge impact on libraries in the next few years, but personally I'm very interested in how e-books will change libraries. Libraries have always done well at integrating new technologies but this is the first time that a technology has the potential to supplant what libraries are best known for-books.

\section{If you had one chance to time travel, when would you travel to and why?}

Maybe go to Hamburg and watch the Beatles in their earliest days?

\section{What would you title your autobiography?}

Don't Let That Man Pick out Any More Books for Me!

(This was a comment a co-worker got from a patron soon after I started in RPL's Outreach Unit where staff select books on behalf of visually impaired and homebound patrons.) 